University in Hamilton, Canada, and their group tested minocycline in combination with each of 1,057 approved drugs. They found 69 nonantibiotic compounds that boosted minocycline's ability to slow the growth of three bacterial species. Three of these drugs rendered multidrug-resistant clinical strains of the pathogen Pseudomonas aeruginosa susceptible to the antibiotic.

One of the three, the antidiarrhoeal drug loperamide, may improve the uptake of minocycline and related antibiotics by the bacteria. The two combined reduced the bacterial load in mice infected with minocyclineresistant Salmonella enterica Typhimurium.

Nature Chem. Biol. doi:10.1038/ nchembio.559 (2011)

\section{GEOENGINEERING}

\section{Aerosols pose climate dangers}

The risks of injecting aerosols into the stratosphere to combat global warming have been underestimated, say Klaus Keller and his team at Pennsylvania State University in University Park.

Some have proposed that adding fine particles and liquid droplets, which reflect heat, to the atmosphere could postpone the need for deep cuts to carbon emissions. But by modelling the economic effects of substituting aerosol injections for carbon cuts, the researchers show that potentially damaging sideeffects of the aerosols - such as depletion of polar ozone and changes in precipitation patterns - could easily wipe out any benefit. And because aerosols disappear quickly whereas greenhouse gases linger, Earth could face even more abrupt and costly climatic change if any aerosol injections were interrupted by, for example, war or the breakdown of international pacts, the researchers say. Clim. Change doi:10.1007/ s10584-010-9961-z (2011)
BIOENGINEERING

\section{Patching up the heart}

Small patches of a protein matrix loaded with stem cells could help to repair the damage caused by a heart attack.

Gordana Vunjak-Novakovic and her colleagues at Columbia University in New York stripped human heart muscle tissue of its cells, leaving behind a porous protein scaffold. They filled this with human mesenchymal progenitor cells, which develop into muscle and other tissues, and then implanted patches of it into the damaged hearts of rat models of heart attack. The patches enhanced the growth of new blood vessels and stopped the left ventricle from enlarging and weakening - common effects of a heart attack.

Instead of forming new vessels or tissues, progenitor cells homed in on the damaged areas and released proteins that stimulated the native tissue to repair itself. Similar patches could deliver other types of cell, such as heart muscle cells created from reprogrammed stem cells, the researchers say.

Proc. Natl Acad. Sci. USA doi:10.1073/pnas.1104619108 (2011)

\section{CLIMATE CHANGE}

\section{Sugar cane cools climate}

The rapid expansion of sugar cane cultivation (pictured) for biofuels in Brazil may be cooling the local climate.

Scott Loarie at the Carnegie Institution for Science in Stanford, California, and his team analysed remotesensing data for factors including land cover, temperature and albedo (reflectivity) in the Brazilian savannah, where sugar cane acreage is on the rise. They found that temperatures in the region increase by an average of $1.55^{\circ} \mathrm{C}$ when natural vegetation is converted to non-cane crops or pasture, largely because of decreased water evaporation

COMMUNITY CHOICE

The most viewed papers in science

\title{
Immune cells promote metastasis
}

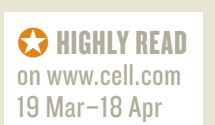

19 Mar-18 Apr

The rapid progression of breast cancer has been linked to immune cells called macrophages. Now researchers have identified a protein that these 'tumourassociated' macrophages (TAMs) secrete that drives metastasis. Erwei Song at Sun-Yat-Sen University in Guangzhou, China, Xuebiao Yao at the University of Science and Technology of China in Hefei and their colleagues found that the most abundant cytokine - a cell-signalling protein produced by TAMs isolated from patients with invasive breast cancer is CCL18. Injection of this molecule into tumourbearing mice boosted metastasis. Meanwhile, human breast cancer cells cultured with TAMs displayed a six- to ninefold increase in invasiveness. Adding an anti-CCL18 antibody tempered this response.

Cancer Cell 19, 541-555 (2011)

and transpiration (evaporation from plants). However, when planted on land already used for agriculture, sugar cane crops cool temperatures by $0.93^{\circ} \mathrm{C}$, thanks to greater evaporation and transpiration, and higher albedo.

The authors cite this as evidence that sugar cane's climate benefits will be greatest if restricted to existing agricultural lands and if the plant's cultivation does not drive deforestation elsewhere. Nature Clim. Change doi:10.1038/ nclimate1067 (2011)

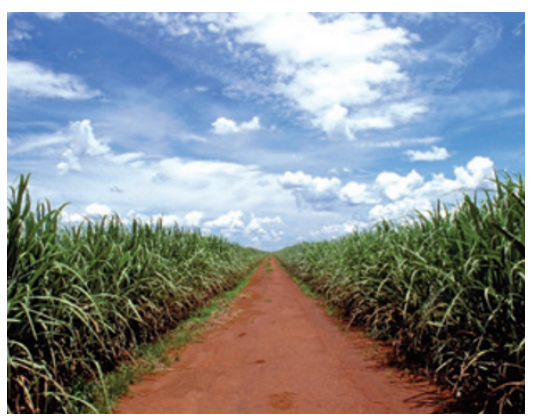

$$
\text { ECOLOGY }
$$

\section{Plant networks crowd neighbours}

Plants that connect and spread through expansive underground networks reduce biodiversity, even in soils that are thought to boost it. This could mean that such 'clonal' species - some grasses, for example - will exacerbate plant biodiversity loss in soils that have been enriched by humans.

Fertilizing soil is known to lower plant-species richness, whereas natural variations in local soil nutrient levels are thought to increase it. Alexander Eilts at the University of Minnesota in St. Paul and his colleagues manipulated nutrient levels in outdoor plots for six years. When nutrient levels varied on a small scale, clonal species dominated by reaching between areas to get more nutrients. When nutrient levels varied over larger scales, or when clonal species were absent, biodiversity was higher.

Because of their underground networks, clonal plants may lower the ability of soil nutrient heterogeneity to support a diversity of plant species. Am. Nat. doi:10.1086/659633 (2011)

\section{$\rightarrow$ NATURE.COM}

For the latest research published by Naturevisit:

www.nature.com/latestresearch 